\title{
Applying Nanotechnology to Human Health: Revolution in Biomedical Sciences
}

\author{
Siddhartha Shrivastava and Debabrata Dash \\ Department of Biochemistry, Institute of Medical Sciences, Banaras Hindu University, Varanasi 221005, India \\ Correspondence should be addressed to Debabrata Dash, ddass@satyam.net.in
}

Received 20 May 2009; Accepted 20 June 2009

Recommended by Chuan-Jian Zhong

\begin{abstract}
Recent research on biosystems at the nanoscale has created one of the most dynamic science and technology domains at the confluence of physical sciences, molecular engineering, biology, biotechnology, and medicine. This domain includes better understanding of living and thinking systems, revolutionary biotechnology processes, synthesis of new drugs and their targeted delivery, regenerative medicine, neuromorphic engineering, and developing a sustainable environment. Nanobiosystems research is a priority in many countries and its relevance within nanotechnology is expected to increase in the future. The realisation that the nanoscale has certain properties needed to solve important medical challenges and cater to unmet medical needs is driving nanomedical research. The present review explores the significance of nanoscience and latest nanotechnologies for human health. Addressing the associated opportunities, the review also suggests how to manage far-reaching developments in these areas.
\end{abstract}

Copyright ( $) 2009$ S. Shrivastava and D. Dash. This is an open access article distributed under the Creative Commons Attribution License, which permits unrestricted use, distribution, and reproduction in any medium, provided the original work is properly cited.

\section{Introduction}

Nanotechnology and nanoengineering stand to produce significant scientific and technological advances in diverse fields including medicine and physiology. In a broad sense, they can be defined as the science and engineering involved in the design, synthesis, characterization, and application of materials and devices whose smallest functional organization in at least one dimension is on the nanometer scale, ranging from a few to several hundred nanometers. A nanometer is one billionth of a meter or three orders of magnitude smaller then a micron, roughly the size scale of a molecule itself (e.g., a DNA molecule is about $2.5 \mathrm{~nm}$ long while a sodium atom is about $0.2 \mathrm{~nm}$ ).

The potential impact of nanotechnology stems directly from the spatial and temporal scales being considered: materials and devices engineered at the nanometer scale imply controlled manipulation of individual constituent molecules and atoms in how they are arranged to form the bulk macroscopic substrate. This, in turn, means that nanoengineered substrates can be designed to exhibit very specific and controlled bulk chemical and physical properties as a result of the control over their molecular synthesis and assembly.
For applications to medicine and physiology, these materials and devices can be designed to interact with cells and tissues at a molecular (i.e., subcellular) level with a high degree of functional specificity, thus allowing a degree of integration between technology and biological systems not previously attainable. It should be appreciated that nanotechnology is not in itself a single emerging scientific discipline but rather a meeting of traditional sciences such as chemistry, physics, materials science, and biology to bring together the required collective expertise needed to develop these novel technologies. The present review explores the significance of nanoscience and latest nanotechnologies for human health (Figure 1). Addressing the associated opportunities, the review also suggests how to manage far-reaching developments in these areas.

\section{Scientific and Application-Oriented Research}

Living cells are full of complex and highly functional "machines" at nanometer scale. They are composed of macromolecules, including proteins. They are involved in practically every process in the cell, such as information transfer, metabolism, andthe transport of substances. 


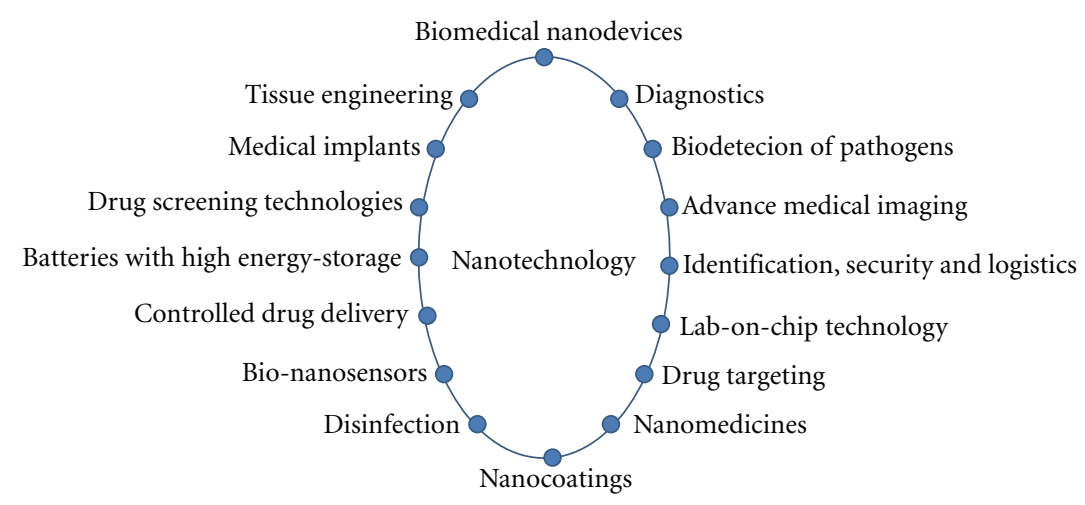

FIGURE 1: Schematic illustration of nanotechnology revolutionizing biomedical sciences.

Nanotechnologies offer new instruments for observing the operation of these machines at the level of individual molecules, even in the living cell [1]. Using atomic force microscopes, it is possible, for example, to measure the bonding forces between trigger substances, such as hormones, and the associated receptor proteins that act as switches in the cell membrane. Biomolecules can be labelled using quantum dots. The intense light of a specific wavelength that these nanocrystals emit enables the path followed by the biomolecules in the cell to be precisely traced [2]. A great deal of this research is concerned with obtaining information on basic biochemical and biophysical processes in healthy and diseased cells. This knowledge can provide the basis for the development of new prevention strategies and therapies. Beside this primarily knowledge-broadening research, research is also underway into numerous possible applications for nanotechnologies in medicine [3, 4]. Research efforts are particularly intensive in the search for new methods and tools for imaging [5], sensing [6], targeted drug [7], and gene delivery systems [8]. More research is also underway into applications in fields such as tissue medical implants [9] and disinfection [10-14]. Clinical applications are currently scarce partly because of stringent safety requirements. Nevertheless, experts expect a great deal from nanomedicine [15] especially in the longer term (Figure 2).

\section{Diagnostics}

The enormous increase in knowledge of the human genome (genomics) and of expression products, proteins (proteomics), makes it possible in an increasing number of cases to trace diseases to abnormalities at the molecular level. In theory, this gives rise to the possibility of making a diagnosis at a very early stage - and of possibly starting treatmenteven before the initial symptoms of the disease appear $[16,17]$. Attention in medicine is, therefore, increasingly focusing on prevention. Neonatal screening (by means of a heel prick) for metabolic diseases is a good example of this [18]. The medical profession has an ever increasing number of technical tools at its disposal for detecting these molecular biomarkers. It is in this field that the impact of nanotechnologies will probably be noticed first (within five years) $[15,19]$. The diagnostic research can be conducted in the laboratory using samples taken from the human body (in vitro research) but it can also be carried out directly on the patient (in vivo). This distinction is important because, in the latter case, the tools/agents have to meet more stringent requirements.

3.1. In the Laboratory. Research into patients' genetic material (DNA) can be conducted to measure gene expressionthe degree of RNA production-in diseased tissue, or to ascertain which variant of a particular gene a person has. Many human genes exist in several forms, which only differ in a single base pair. These are known as single nucleotide polymorphisms (SNPs). The corresponding protein variants may differ from each other in a single amino acid and then display a considerable difference in functionality. SNPs are the root of all kinds of genetic disorders and also affect a person's sensitivity to chemical substances, including medicines. This refers to their therapeutic effect as well as their side effects [20]. Genetic research offers major possibilities for identifying gene types that predispose a person to certain diseases and for achieving better matches between individual patients and the medicines they are prescribed [21,22].

DNA chips used for analyzing DNA have been available for a few years now. They are currently widely used in scientific, biomedical research but they are rarely used in clinical practice. The chips comprise an inert support which carries microarrays of hundreds to thousands of singlestrand DNA molecules with different base sequences. DNA from a tissue sample that has been labelled with a radioactive or fluorescent material can be identified on the basis of the place on the chip where it binds to the chip DNA. The Dutch Cancer Institute has been using a DNA chip since 2003 to predict the spread of breast tumours on the basis of gene expression profiles. This information makes it much easier than it was in the past to determine which patients would benefit from supplementary chemotherapy after the tumour has been surgically removed $[23,24]$. Similar chips are being developed for the diagnosis of leukaemias [25, 26] and mouth and throat tumours [27]. DNA chips and other 


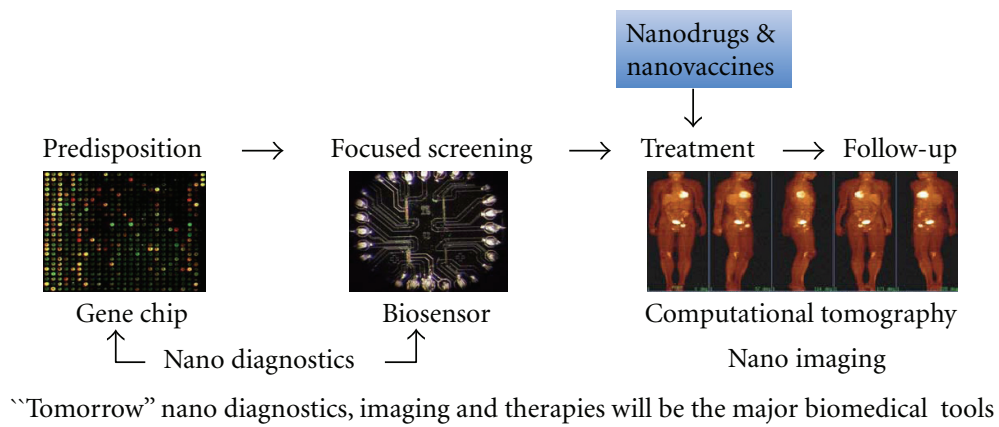

Figure 2: Nanotechnologies in medicine.

biochips were originally an achievement of microtechnology but miniaturisation is advancing here too, as with computer chips. Nanotechnologies are also increasingly playing a role in producing the chips and in increasing their detection sensitivity and reliability [28-31].

A new nanotechnological analytical method uses quantum dots [5]. DNA in a sample is identified on the basis of its bonding to DNA molecules of a known composition embedded in micrometre-sized polymer spheres containing various mixtures of quantum dots, each of which provides a unique spectral bar code (colour code) [32]. American researchers have used this method to study SNPs in genes that code for enzymes of the cytochrome P450 family which are involved in the breakdown of substances (including medicines) in the body [33]. The method is very suitable for studying large quantities of samples on many SNPs simultaneously (multiplex analyses).

In theory, the composition of DNA molecules can also be ascertained by pulling them through nanopores in a membrane by means of an electric potential difference. The base sequence can be deduced from the time profile of the electric current through the pores [34]. Researchers have now used this method to identify a mutation in an HIV gene that makes the virus resistant to a particular medicine [35]. If this method, which is still being developed, can be perfected, it will result in a much faster way of determining the base sequence of DNA than has thus far been available. This would involve having to place hundreds of pores on a chip.

The aforementioned techniques would, in principle, also be suitable for identifying other biopolymers, such as proteins and carbohydrates. Nevertheless, American researchers have succeeded in developing a chip to detect prostate cancer. The chip contains around one hundred cantilever sensors (micrometre-sized, nanometres thick miniscule levers), which are coated on one side with antibodies to prostatespecific antigen (PSA), a biomarker for that disease. Bonding of PSA from a sample placed on the chip bends the cantilevers several nanometres, which can be detected optically. This enables clinically relevant concentrations of PSA to be measured $[36,37]$. Antibodies placed on nanowires can be used in a similar way to detect viruses, in a blood sample, for example $[38,39]$. The bonding of a single virus particle to an antibody results in a change in the nanowire's electric conductance. The method is extremely sensitive, which means that an infection can be detected at a very early stage. It is also suitable for multiplex analyses. Work is also underway on sensors based on carbon nanotubes, for use in microarrays [40]. Detection methods based on cantilevers, nanowires or nanotubes offer the added advantage that it is not necessary to label the sample.

Labs-on- $a$-chip are pocket-sized laboratories. They can be used for analyzing biopolymers and also for research and for manipulating cells. They are expected to play an important role in the further development of biosensors for the detection of pathogenic bacteria [41]. In due course, there will also be possibilities for point-of-care applications, in which simple analyses can be made in the general practitioner's surgery or in the patients' homes and carried out by the patients themselves [42]. Researchers of the University of Twente are currently working on the development of a labon-a-chip for measuring lithium concentrations in the blood [43]. A chip of this kind would enable patients who use psychopharmaceuticals based on lithium to keep the lithium concentration in their blood at the right level. The ease of use would be comparable with that of current devices that enable diabetic patients to measure glucose levels in their blood. Photonic explorers for bioanalysis with biologically localised embeddings (PEBBLEs) are a final example. These sensors are a few hundreds of nanometers in size and are composed of an inert capsule, made of polymers, for example, containing an indicator colouring agent that emits light as soon as a substance being analysed diffuses through the capsule to the inside and binds with the colouring agent [44]. PEBBLEs were developed for measuring concentrations of small ions and molecules-such as ions of hydrogen, calcium, magnesium and zinc, or glucose-in living cells. Once the nanocapsules have been introduced into a cell, their light emission (and cessation of emission) can be monitored using a microscope. Tools of this kind are useful when studying certain diseases. For example, an abnormal zinc balance is a characteristic of brain disorders such as Alzheimer's disease and Parkinson's disease [45].

3.2. In Vivo Diagnostics and Imaging. In the case of in vivo diagnostics, patients are given contrast agents or radiopharmaceuticals. Their specific properties mean that these agents are useful in imaging pathophysiological changes and functional changes such as changes in blood flow in cells, 
tissue, and organs. The term molecular imaging is often used, as today's imaging techniques are increasingly concerned with making molecular biomarkers of disease processes visible, for instance, a receptor protein on the surface of a cancer cell. To this end, beside being given a contrast agent (the imaging component), a carrier molecule or particle is also given a molecule that specifically binds to the biomarker, such as an antibody (the targeting component). Various techniques have been developed, each with its own contrast agents and imaging equipment: methods based on ultrasonic vibrations, radioactive substances (including positron emission tomography, PET), magnetic resonance imaging (MRI), and fluorescent substances. Each has its own possibilities for applications and its own restrictions [46]. Imaging that focuses on molecular biomarkers makes early detection of diseases possible and provides information on appropriate therapies. Imaging is also very suitable for monitoring, evaluating and optimising treatment, that is, being provided [16]. Nanotechnologies offer numerous possibilities for improving existing and designing new imaging techniques [47-49].

Nanoparticles of perfluorohydrocarbons combined with a lipid layer have multiple uses. They are suitable as an ultrasonic contrast agent [50]. If gadolinium compounds or radioactive substances such as technetium-99 are combined with the lipid layer of the nanoparticles, they are also suitable for MRI, or scintigraphic imaging [51]. Given the right targeting molecule, the particles can make pathogenic changes in blood vessels visible. The nanoparticles are currently being studied for use as a contrast agent for the diagnosis of atherosclerosis, thrombosis, and (tumour) angiogenesis. A clinical study is expected to start within a few years [48].

Superparamagnetic nanoparticles of iron oxide are now being used clinically as an MRI contrast agent [52]. They accumulate after intravenous administration in the liver, the spleen, and the lymph glands, thereby enabling studies of those organs [53]. Patient-based research has indicated that they can also increase detectability of tumour metastases in lymph glands [54]. Combined with dendrimers (Figure 3), the particles can be used for marking living cells. Magnetodendrimers of this kind make it possible to, for example, monitor the migration and division of transplanted cells in the body. The method, which has already been used successfully on laboratory animals [55], may prove to be of valuable assistance in the future in stem cell therapy. Gadolinium dendrimers are also being developed for use as contrast agents [56]. The first of these agents are almost ready for introduction on the market [17]. Depending on their size and solubility in water or fat, they are suitable for examining blood vessels, kidneys, liver, or lymph glands $[57,58]$.

Optical imaging techniques use fluorescent colouring agents which are taken orally or injected and then accumulate in a tumour, for example. The tumour cells fluoresce when irradiated with laser light. Because the laser light cannot penetrate deep into the body, this technique can only be used for imaging tumours in or just below the skin or in tissue, that is, accessible using an endoscope $[5,59]$.
Intensive research has been underway for several years now into new optical methods based on the use of nanoparticles. Quantum dots are at the most advanced stage (Figure 4) of development [60-63]. These nanocrystals have the advantage over colouring agents that they fade less quickly over time and do not react with cell components. Moreover, quantum dots of different colours can be made to fluoresce with laser light of the same wavelength, which makes multiplex applications possible. Nanoparticles have already been successfully used in cell cultures and laboratory animals to colour biomarkers on the surface of cancer cells [64], to monitor the development of cell lines in a frog embryo [65], and to make blood vessels visible in mice [66] as well as lymph glands in pigs [67]. The hope is that the latter application will in due course improve the possibilities for tracing tumour metastases [66]. All these applications are based on the fact that nanomaterials because of their minute size can easily enter even the smallest compartment of the cell [68].

The quantum dots are provided with a layer of lipids or polymers, to prevent heavy metals from being released. However, before clinical applications can be considered, research will have to show that coatings of this sort are also effective in the long term [63]. Contrast agents can sometimes also act as a medicine. For example, under the influence of laser light of a certain wavelength and in the presence of oxygen, some fluorescent colouring agents produce toxic substances which can destroy tumour cells by oxidation. In addition, it is theoretically possible to combine diagnosis and therapy by providing nanoparticles not only with targeting molecules and contrast agents but also with active substances. The nanoparticle then also acts as a drugdelivery system.

\section{Therapy}

4.1. Drug Delivery. Many substances that could, in theory, be used as medicines have the disadvantage that they are hardly, if at all, able to reach the diseased organs or tissues in the body. There are various possible reasons for this:

(1) the substance is hardly, if at all, soluble in water;

(2) the substance is broken down in the body or inactivated before it reaches its target;

(3) the substance is hardly, if at all, capable of passing certain biological barriers (cell membranes, placenta, blood-brain barrier);

(4) the substance distributes nonspecifically to all kinds of tissues and organs.

Substances of this kind are, therefore, ineffective or lead to undesirable adverse side effects. As long as a hundred years ago, German microbiologist Paul Ehrlich conceived of the idea of using "magic bullets" to direct medicines at their target more effectively [48]. This idea was taken up again at the end of the 1960s and researchers have since been developing such drug delivery systems [69]. Their miniscule dimensions mean that all kinds of nanoparticles are suitable 


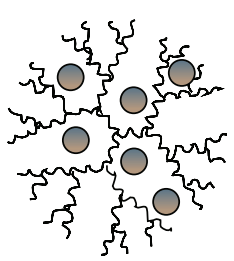

Active substance

(a)

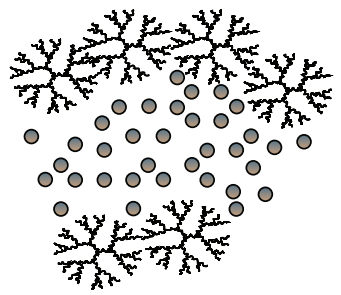

Active substance

(b)

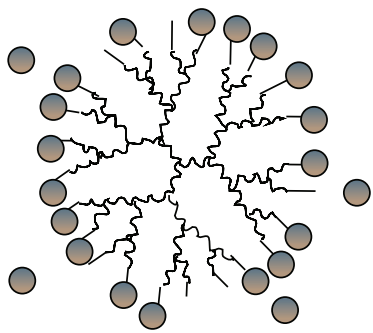

Active substance

(c)

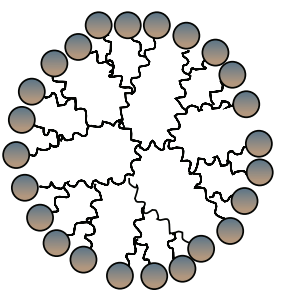

Active substance

(d)

Figure 3: Principal ways to use dendrimers as drug carrier (Source: Schmid et al., Nanotechnology assesments and prospective, 2006, Springer).
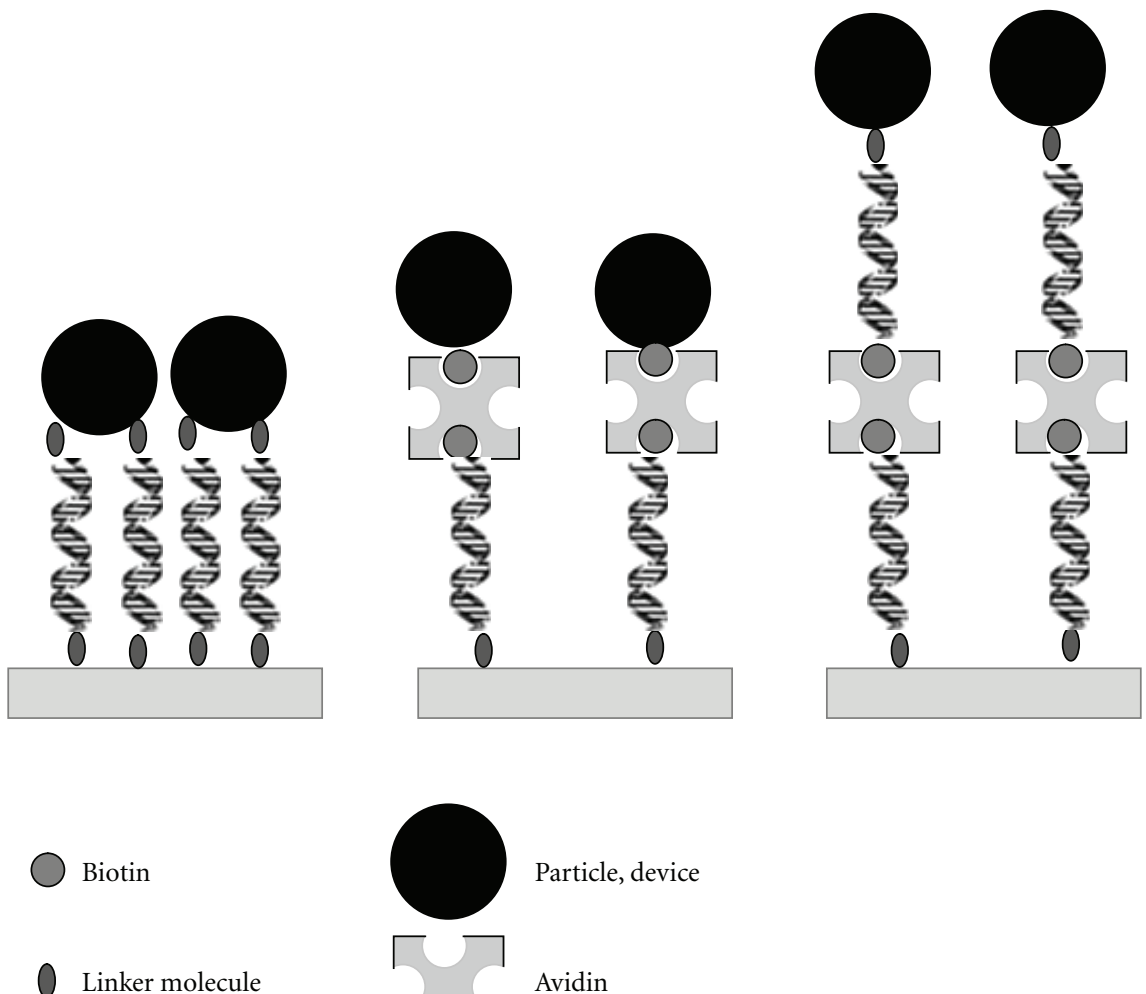

Linker molecule

Avidin

FIGURE 4: Single stranded DNA and quantum dot as building blocks for the construction of complex 3-dimensional structures which can be used for biosensors. (Source: Schmid et al., Nanotechnology assesments and prospective, 2006, Springer).

for use in systems of this kind [48, 70-73]. Depending on the type of particle, the active substance can be encapsulated or attached to the surface. This means that even if they dissolve poorly in water, they can be transported in an aqueous solution, such as blood, and are better protected against degradation by enzymes, for example. A suitable coating on the nanoparticle can prevent identification and removal by the immune system [74-76].

Selective accumulation in the target organ or tissue can arise through various mechanisms [68]. The first mecha- nism is passive. An example of this would be to use the high permeability of the walls of blood vessels and the reduced lymph drainage in tumour tissue [77]. However, it is also possible to provide nanoparticles with "targeting molecules" (e.g., specific antibodies or folic acid), which ensure that the delivery system primarily bonds to the diseased tissue (Figure 5). However, this can aid detection by the immune system [78]. When provided with suitable targeting molecules, some nanoparticles are able to transport medicines across the blood-brain barrier to treat brain 


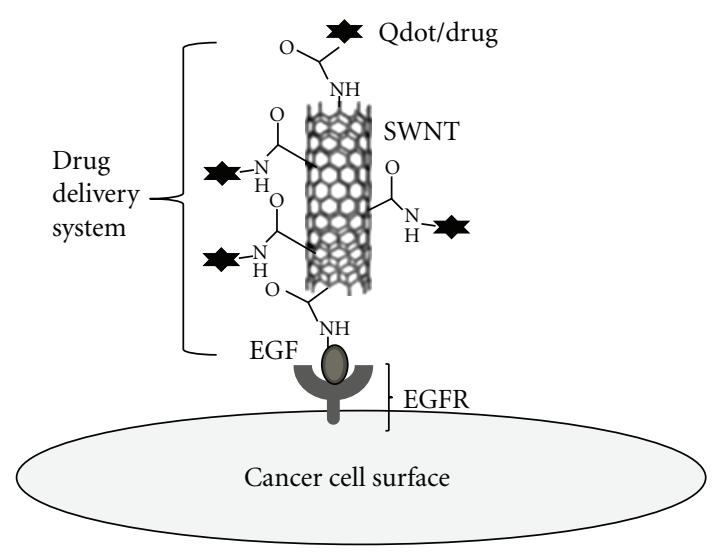

Figure 5: Nanotube-based drug deliver delivery/imaging system. Schematic showing nanotube bundles bioconjugated with EGF targeting the cell surface receptor EGFR on the cancer cell on one side and with quantum dot (for imaging) or drug molecule (for delivery) on other side. (Modified figure; original source: Bhirde et al., ACS Nano, 2009, doi: 10.1021/nn800551s).

tumours, for example $[79,80]$. The cells being treated can then take up the delivery system containing the active substance by means of endocytosis.

Combining the delivery systems with contrast agents, fluorescent, or radioactive substances also makes it possible to use imaging techniques to monitor how successful the selective transport to the destination has been $[81,82]$. Once it has reached the target area, the active substance has to be released from the carrier at the correct rate. This can occur spontaneously by gradual diffusion, in combination with the delivery system's degradation or otherwise. It may also occur as a result of special conditions at the destination, such as a different acidity level [83], salt concentration, temperature, or the presence of certain enzymes. The accumulation of the delivery system and/or the release of the active substance at the right place can also be controlled from outside by influencing conditions in the target organ or tissue by means of magnetic fields [84-86], near-infrared radiation [87], ultrasonic vibrations [88], or heat [89-91]. The delivery system used and the external treatment have to be precisely matched to each other for this purpose.

The requirements that delivery systems have to fulfill are as follows:

(1) their residence time in the blood must be long enough to enable accumulation in the target tissue;

(2) they must be capable of containing sufficient active substance;

(3) the systems or their degradation products must have a favourable toxicity profile;

(4) they must have a shelf life long enough to allow storage and distribution;

(5) the effectiveness must be in proportion to the costs.

Research into the suitability of a large variety of nanoparticles for use as a delivery system is currently underway $[48,70$
73]. Which particles are most suitable depends on the active substance that has to be transported, the target organ, and the method of administration (oral, inhalation, dermal, by injection). Some particles, such as nanoparticles of polymer or of solid fat, appear to be usable for transporting a wide range of substances. The scope for using other, especially inorganic, nanoparticles is smaller. Most delivery systems are currently being developed for transporting antitumour agents, genetic material (gene therapy), as well as proteins and peptides. Nanoparticles of polymers as delivery systems for active substances have been taking place since the mid1970s. The usefulness of other systems, such as nanoparticles of solid fat, dendrimers, fullerenes, and nanocrystals of the active substance, only began to be studied in the early or mid-1990s. There are now various medicines with delivery systems on the market and many are in the clinical study phase [69]. Magnetic nanoparticles stand first in this classification. The idea of using magnetic micro- and nanoparticles can be traced back to late 1970s. The work by Widder et al. $(1978,1979)[92,93]$ employed magnetically responsive microspheres to deliver antitumor drugs. Since the time of these studies, numbers of groups have demonstrated the efficacy of this approach in numerous small animal studies $[94,95]$. Although magnetic targeting has been successful in a number of such studies, there remain only a small number of clinical trials to date. The first phase I clinical trial of magnetically targeted drug delivery was performed by Lubbe et al. in 1996 [84]. In this study, epirubicine was complexed to nanoparticles on the basis of electrostatic interactions between phosphate groups bound to the surface of particles and amino sugars present within the drug. Similarly, few more clinical trials have been performed with promising results $[96,97]$, thus promoting magnetic nanoparticles as another tool for treatment of variety of diseases.

The future for drug delivery systems is expected to be bright, even if significant obstacles still have to be overcome [69]. Obstacles include the development of methods to increase the specificity of delivery systems for target cells, to more precisely regulate the bioavailability of active substances in the target tissue, and to get active substances to the destination within the cell more efficiently.

4.2. Nanoparticles as Medicines. Besides acting as a delivery system, in some cases nanoparticles can act as an active substance. Once they have found their way through the bloodstream into a tumour, or have been injected directly into it, metal-containing nanoparticles can be heated using near-infrared radiation [98, 99] or a rapidly oscillating magnetic field [100] so that the tumour cells die. As yet, this relates to research conducted using laboratory animals. It may also be possible to use single-wall carbon nanotubes in a similar way $[101,102]$. In vitro studies have in fact shown that if combined with folic acid as targeting molecules, the tubes are selectively taken up by cancer cells. These cells can then be killed by using near-infrared radiation to heat the tubes (Figure 5). Healthy cells appeared to take up few, if any, nanotubes and not to be affected by the near-infrared radiation [103]. 
Similarly, the temperature enhancement which occurs in a magnetic nanoparticle (MNP) system under the influence of an external high frequency magnetic field has found application in cancer therapy by hyperthermia [104, 105]. In magnetically mediated hyperthermia, one deposits magnetic material in the tumour which is heated by the means of an external alternating magnetic field. Beside the application of macroscopic magnetic implants "seeds" which are currently in clinical use for special cancer types, recent studies are focused on magnetic nanoparticles as their heat generation potential appears beneficial and they provide the opportunity of direct tumour targeting through blood circulation [106]. Beside the opportunity of a very localized heat generation, the application of magnetic nanoparticles offers the possibility of a self-limitation of the temperature enhancement by using a magnetic material with suitable Curie temperature [107]. In all cases, it is advantageous to achieve the temperature enhancement needed for a special application with as low as possible amount of MNP. This is particularly important for applications where target concentration is very low, for instance, in antibody targeting of tumours.

Recent in vitro and in vivo studies have revealed that silver nanoparticles are endowed with innate antiplatelet properties [108], thus indicating their potential as future antithrombotic drugs. Further studies are already underway to characterize the fibrinolytic behavior of these nanomaterials in various pathological conditions like diabeties, stroke, and myocardial infarction (S. Shrivastava et al., unpublished data).

4.3. Passive Implants and Tissue Engineering. Artificial joints, such as artificial hips, normally have a life of around ten to fifteen years, after which complications occur, such as wear or implant loosening, and further operations are required [109]. Nanotechnologies could help reduce these problems. The implants, which are usually made of titanium or alloys of cobalt and chromium, can be provided with a thin layer of a nanocrystalline structure, which is harder and smoother and consequently more resistant to wear. This would also result in less wear of the artificial socket, which is generally made of a special type of polyethylene. Moreover, the layer would ensure that the body better tolerates the implant (better biocompatibility). The suitability of various materials for use as a coating is currently being studied: diamond, metal ceramic, and hydroxyapatite [110]. The latter material is a natural component of bone, $70 \%$ of which consists of the mineral hydroxyapatite, with the remaining 30\% consisting of organic fibres (collagen). Hydroxyapatite has been used as a coating in implants for some time but new production methods now make it possible to apply layers with a grain size in the nanometre, rather than the micrometre scale. This makes their structure more like that of natural hydroxyapatite in bone, which likewise has a nanocrystalline structure (grain size less than $50 \mathrm{~nm}$ ). This aids biocompatibility. The layer can even encourage the growth and bonding of the surrounding bony tissue. In vitro research has shown that bone-forming cells (osteoblasts) adhere better and deposit more calcium on materials with a grain size in the nanometre range than on conventional materials with a grain size in the micrometre range [110 113]. This is presumably related to the higher absorption of proteins that stimulate cell adhesion [114]. Bone resorbent cells (osteoclasts) also function better on these nanomaterials. Proper, coordinated function of both types of cells is essential for the formation and maintenance of healthy bony tissue and, therefore, for strong bonding between the implant and the surrounding bone $[109,115,116]$. This is extremely important for implants that are attached without the use of bone cement. Implants provided with a hydroxyapatite layer with a nanostructure are currently being tested in patients, in 2000, a patient in the Maastricht University Hospital was the first to receive an artificial hip with such a coating. Nanoparticles of hydroxyapatite can also be introduced directly into damaged bones to accelerate the repair of bony tissue. In recent years, a few medicines have been admitted that work according to this principle. Implant coatings with a nanostructure based on diamond and metalceramic are still at the research stage. Their main benefits are hardness, smoothness, corrosion resistance, and good bonding to the implant [110].

The mechanical properties and biocompatibility of implants can also be improved by providing the material which is used to make the implants with a nanostructure. This is possible by applying a thin layer of titanium dioxide with nanopores. An added advantage of this approach is that the layer can be made in a way that metal ions with an antiseptic effect, such as copper ions, are slowly released. This reduces the likelihood of bacterial infections, which are a frequent complication with implants [117]. Another possibility is to make the implants from nanopowders of titanium dioxide or aluminium oxide using a sinter process. Promising alternative materials include organic polymers with a nanostructure and composite materials of organic polymers into which nanofibres of carbon or nanoparticles of titanium, aluminium, or hydroxyapatite have been mixed $[109,118,119]$. The advantage of the organic polymers is that they dissolve gradually while new bony tissue is being formed. Studies are also underway of the possibilities of generating bone with the help of scaffolds of carbon nanotubes [120].

The orthopaedic applications are closest to being used on patients [109], but biodegradable scaffolds of nanofibres consisting of natural or synthetic organic polymers are already used to cultivate other tissues, such as cartilage, muscle tissue, nerve tissue, and vascular tissue in vitro [121]. Here too, the goal of the nanostructure is to imitate the natural extracellular matrix. Researchers recently succeeded in using nanofibres to regenerate brain tissue in vivo. Young and adult hamsters, which had been blinded as a result of intentionally caused brain damage, had their sight restored within a few weeks of scaffold-forming nanomaterial being injected into the brain [122]. It may also be possible to use the method in the future to repair damaged human nerve tissue. Stents are a completely different type of implant. They are small tubes of woven thread used to dilate blood vessels. Inflammatory reactions often occur and lead to the blood 

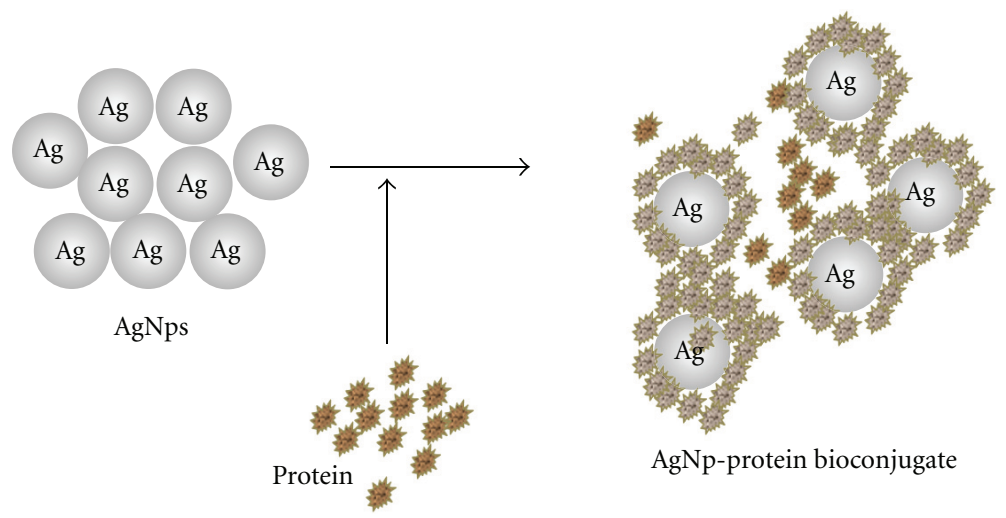

FIGURE 6: Schematic showing interaction of silver nanoparticles (AgNps) with protein leading to the formation of protein encapsulated bioconjugate.

vessel closing again. This problem is dealt with using stents with a coating of aluminium oxide which is provided with nanopores. A radioactive substance can be applied to them, which prevents the stent from clogging. The pores ensure that sufficient radioactive material can be introduced and that it is released very gradually. The functionality and safety of these stents still have to be confirmed in animal trials. Research is also underway into the possibility of using the lotus effect: a coating of titanium compounds is used to prevent clotting reactions owing to conformation changes in proteins in the blood caused by their contact with the stent wall [123].

4.4. Active Implants. Active implants are implants that contain a source of energy. They can be divided into two groups on the basis of their function. The first category comprises implants for administering medicines, such as insulin pumps and morphine pumps. They have been in use for a long time. Work has also been underway for several years on implantable microchips for the storage and controlled release of active substances [124, 125]. The benefits of this approach to administering medicines include the fact that the medicines go directly to the location where they are needed and can, if required, be administered at varying rates. The release could also be controlled by a biosensor that responds to physiological parameters. The first system of this kind is soon due to be tested on patients [126].

The second group comprises neural prostheses, which are intended to repair or take over nerve functions. For instance, they bridge damaged nerve paths, provide impulses for muscles or replace senses. This category includes cochlear implants (for restoring hearing), pacemakers and defibrillators (for regulating the heart beat), bladder stimulators (for controlled emptying of the urinary bladder by spinal cord lesion patients), deep-brain stimulators (to combat tremor in patients with Parkinson's disease), as well as peroneus stimulators (to combat drop foot).

These are all currently used in patients and some have been in use for decades. On the other hand, retinal implants to restore the sight in patients with a damaged retina are still in development. In recent years, a great deal of research has been conducted into this in the United States, Germany, and Japan. Although considerable advances are being made and the first clinical tests are already underway, some major obstacles still have to be overcome. It will probably be years before "artificial retinas" are as common as the other neural implants [127]. For some years now, various research groups in the United States have also been working on neuroprostheses that enable devices to be operated by thought [128-133]. To this end, one or more chips with electrodes are fitted to the motor cerebral cortex, which register the electrical signals associated with thoughts. These prostheses are also referred to as brain-machine interfaces. They have now succeeded in enabling rats to operate handles by "brain power" and monkeys to operate the cursor of a computer or a robot arm $[130,131]$. A few years ago, an amyotrophic lateral sclerosis (ALS) patient had an electrode implanted in the cerebral cortex to enable him to operate a computer [134]. In 2004, a neuroprosthesis was fitted to a paralysed man. It enables him to operate the cursor of a computer by thought, play video games, operate a light switch, and select a television channel. The findings were presented at the annual meeting of the American Academy of Physical Medicine and Rehabilitation, in Phoenix in October 2004 [135]. The ultimate goal, which is still faroff, is to enable patients to operate arm or leg prostheses or even to restore their control of their paralysed limbs $[129,132]$.

Conversely, it also proved possible to control rats remotely by administering electrical stimuli in the parts of the brain involved in touch and in experiencing pleasant feelings [136, 137]. These so-called "robotrats" could be used to search for victims underneath the rubble of collapsed houses, to detect landmines, or to be used as mobile biosensors. All these active implants are essential products of microtechnologies but nanotechnologies may play an important role in their improvement and further development. Research is mainly concerned with increasing functionality, fixation in the surrounding tissue, and biocompatibility by modifying the surface at the nanoscale [138]. For example, electrodes with a nanoporous surface are being developed for 
retinal implants. This nanostructure increases the electrodes' surface area by a factor of one hundred, which is necessary for proper signal transfer from the electrodes to the tissue [139]. The microelectrodes of neuroprostheses that register electrical signals in the brain often only work for a few weeks. They do not usually become defective but the surrounding tissue gets damaged and nonconductive scar glial-cell tissue grows. In vitro research has shown that a nanoporous surface structure reduces glial-cell adhesion and promotes the formation of outgrowths of nerve cells [140]. A possible explanation for the stimulating effect on the nerve cells is that they are naturally embedded in an extracellular matrix with a nanostructure of microtubuli and laminin. To combat rejection reactions or infections, coatings can be applied that release medicines gradually [141]. An antiseptic layer based on silver nanoparticles is already being used in Germany on cochlear implants [142]. Other examples of contributions made by nanotechnologies to active implants include the membranes with nanopores in microchips for drug delivery [143] and batteries with a higher energy-storage capacity [144].

\section{Other Applications}

5.1. Disinfection. The disinfectant effect of silver has long been known but the use of silver in combating pathogenic microorganisms decreased with the emergence of organic antibiotics. The increasing resistance of bacteria to antibiotics has resulted in renewed interest in silver as a disinfectant. The antiseptic effect is based on silver ions [145]. They block the enzymes required for oxygen metabolism, destabilise the cell membrane, and block cell division. Bacteria are not expected to develop resistance to silver, owing to the diversity of the working mechanisms. Especially in the form of nanoparticles, silver is extremely effective thanks to the large contact area with the environment [10]. Moreover, the particles have the advantage that they can be readily integrated with other materials like (Figure 6) globular or fibrous proteins (communicated data) and polymers [146]. The nanoparticles then act as depots that continually release new silver ions [147]. When applied to medical instruments or implants, antimicrobial layers of this kind can help reduce the number of infections. Current research is studying uses on catheters, cochlear implants and in bone cement [148150]. Antimicrobial wound dressings containing nanocrystalline silver are already on the market [151].

Titanium dioxide nanoparticles also have a bactericidal effect. This is based on a photocatalytic effect. Under the influence of ultraviolet radiation and in the presence of water and oxygen, the particles form extremely reactive molecules (radicals), such as hydroxyl and perhydroxyl radicals, which kill microorganisms [152]. Titanium dioxide can be used to produce antiseptic surfaces that only work in the presence of UV radiation. Fullerenes also have an antimicrobial effect in the presence of light [153]. Various antimicrobial products based on nanoparticles are already on the market [154].

5.2. Identification, Security, and Logistics. Radio Frequency Identification labels (RFID labels) consist of a microchip to which a radio antenna is attached. The chip can contain information on a product that contains it or to which it is attached. A scanning device can activate the chip by means of the antenna, which in turn transmits the information stored in the chip. The labels are used for identification and security purposes and for following flows of goods. They have been in use for some time, for locating stolen cars and bicycles, for example, and for identifying domestic pets and cattle. The labels are a product of microtechnology but nanotechnologies offer possibilities for making them smaller and cheaper. This is expected to increase their use considerably. RFID labels are already used in hospitals and care institutions. They are used to prevent newborns from being abducted or confused or demented patients from wandering away unnoticed [155]. They are also increasingly being used for identifying patients or samples taken from patients, alongside or instead of labels with bar codes [155, 156]. This is to enable an early response when the wrong patient is taken to an operating room, for example [157]. They are also expected to reduce the number of wrong blood transfusions [158]. The labels can also simplify the tracing and localisation of expensive hospital equipment, making it easier to trace medicines and to help in combating drug counterfeiting [155]. Implanting RFID labels in victims of disasters can facilitate their subsequent identification [159].

Meanwhile, RFID labels the size of a grain of rice are available for implantation under the skin. The Food and Drug Administration in the United States approved a label of this kind in 2004. A person's medical record can be stored on the chip. The idea behind this is that faster availability of the right medical information could save a person's life in an emergency. Apart from health care, these kinds of chips are also finding important role in agriculture and food technologies [160].

\section{Summary}

The multidisciplinary field of nanotechnology's application for discovering new molecules and manipulating those available naturally could be dazzling in its potential to improve health care. The spin-offs of nanobiotechnology could be utilised across all the countries of the world.

In the future, we could imagine a world where medical nanodevices are routinely implanted or even injected into the bloodstream to monitor health and to automatically participate in the repair of systems that deviate from the normal pattern. The continued advancement in the field of biomedical nanotechnology is the establishment and collaboration of research groups in complementary fields. Such collaborations have to be maintained not only on specialty field level but also internationally. The successful development and implementation of international collaborations fosters a global perspective on research and brings together the benefits to mankind in general. However, nanotechnology in medicine faces enormous technical hurdles in that long delays and numerous failures are inevitable. This is because the effort needed to produce nanoscale biomedical or therapeutic devices is highly interdisciplinary. 
As we have seen, it touches on numerous established disciplines, encompassing elements of physiology, biotechnology, chemistry, electrical engineering, and materials science, to name just a few of the fields involved. Obviously, this broad sweep of knowledge is difficult for any one investigator to master fully. The breadth of the effort constitutes just one of the major barriers to entry in the field. Other challenges include inadequate funding, the raw complexity of biology, the fashion in which biologists hold and distribute information, and cultural differences between engineers and biological scientists. Likewise, it should not be taken for granted the dangers and negative consequences of nanobiotechnology when applied in warfare, in the hands of terrorists and disasters associated with its application in energy generation when and wherever it strikes, or the risks associated with nanoparticles in blood circulation. It should be appreciated that nanotechnology is not in itself a single emerging scientific discipline but rather a meeting point of traditional sciences like chemistry, physics, biology, and materials science to bring together the required collective knowledge and expertise required for the development of these novel technologies.

\section{Acknowledgments}

This research was supported in part by grants received by D. Dash from the Department of Biotechnology (DBT), Government of India, and the DST Unit on Nanoscience and Technology (DST-UNANST), Banaras Hindu University.

\section{References}

[1] C. Zandonella, "Cell nanotechnology: the tiny toolkit," Nature, vol. 423, no. 6935, pp. 10-12, 2003.

[2] E. Klarreich, "Biologists join the dots," Nature, vol. 413, no. 6855, pp. 450-452, 2001.

[3] A. Curtis and C. Wilkinson, "Nantotechniques and approaches in biotechnology," Trends in Biotechnology, vol. 19, no. 3, pp. 97-101, 2001.

[4] B. Roszek, W. H. De Jong, and R. E. Geertsma, "Nanotechnology in medical applications: state-of-the-art in materials and devices," Tech. Rep. 265001001, RIVM, Bilthoven, The Netherlands, 2005.

[5] W. C. W. Chan and S. Nie, "Quantum dot bioconjugates for ultrasensitive nonisotopic detection," Science, vol. 281, no. 5385, pp. 2016-2018, 1998.

[6] A. Vaseashta and D. Dimova-Malinovska, "Nanostructured and nanoscale devices, sensors and detectors," Science and Technology of Advanced Materials, vol. 6, no. 3-4, pp. 312318, 2005.

[7] R. Langer, "Drugs on target," Science, vol. 293, no. 5527, pp. 58-59, 2001.

[8] S. Jin and K. Ye, "Nanoparticle-mediated drug delivery and gene therapy," Biotechnology Progress, vol. 23, no. 1, pp. 3241, 2007.

[9] E. Sachlos, D. Gotora, and J. T. Czernuszka, "Collagen scaffolds reinforced with biomimetic composite nano-sized carbonate-substituted hydroxyapatite crystals and shaped by rapid prototyping to contain internal microchannels," Tissue Engineering, vol. 12, no. 9, pp. 2479-2487, 2006.
[10] S. Shrivastava, T. Bera, A. Roy, G. Singh, P. Ramachandrarao, and D. Dash, "Characterization of enhanced antibacterial effects of novel silver nanoparticles," Nanotechnology, vol. 18, no. 22, pp. 225103-225111, 2007.

[11] D. Nepal, S. Balasubramanian, A. L. Simonian, and V. A. Davis, "Strong antimicrobial coatings: single-walled carbon nanotubes armored with biopolymers," Nano Letters, vol. 8, no. 7, pp. 1896-1901, 2008.

[12] A. Panacek, L. Kvitek, R. Prucek, et al., "Silver colloid nanoparticles: synthesis, characterization, and their antibacterial activity," Journal of Physical Chemistry B, vol. 110, no. 33, pp. 16248-16253, 2006.

[13] J. R. Morones, J. L. Elechiguerra, A. Camacho, et al., "The bactericidal effect of silver nanoparticles," Nanotechnology, vol. 16, no. 10, pp. 2346-2353, 2005.

[14] C. Baker, A. Pradhan, L. Pakstis, D. J. Pochan, and S. I. Shah, "Synthesis and antibacterial properties of silver nanoparticles," Journal of Nanoscience and Nanotechnology, vol. 5, no. 2, pp. 244-249, 2005.

[15] D. F. Emerich and C. G. Thanos, "Nanotechnology and medicine," Expert Opinion on Biological Therapy, vol. 3, no. 4, pp. 655-663, 2003.

[16] R. Lamerichs, T. Schäffter, Y. Hämisch, and J. Powers, "Molecular imaging: the road to better healthcare," MedicaMundi, vol. 47, no. 1, pp. 2-9, 2003.

[17] European Science Foundation, "Nanomedicine-An ESFEuropean Medical Research Councils (EMRC) forward look report," European Science Foundation, Strasbourg, France, 2005, http://www.esf.org/research-areas/medical-sciences/ publications.html.

[18] Health Council of the Netherlands, "Neonatale screening," The Hague: Health Council of the Netherlands, November 2005.

[19] P. Alivisatos, "The use of nanocrystals in biological detection," Nature Biotechnology, vol. 22, no. 1, pp. 47-52, 2004.

[20] C. Kimchi-Sarfaty, J. M. Oh, I.-W. Kim, et al., "A "silent" polymorphism in the MDR1 gene changes substrate specificity," Science, vol. 315, no. 5811, pp. 525-528, 2007.

[21] P. Galvin, "A nanobiotechnology roadmap for highthroughput single nucleotide polymorphism analysis," Psychiatric Genetics, vol. 12, no. 2, pp. 75-82, 2002.

[22] J. J. McCarthy and R. Hilfiker, "The use of single-nucleotide polymorphism maps in pharmacogenomics," Nature Biotechnology, vol. 18, no. 5, pp. 505-508, 2000.

[23] L. J. Van't Veer, H. Dai, M. J. Van de Vijver, et al., "Gene expression profiling predicts clinical outcome of breast cancer," Nature, vol. 415, no. 6871, pp. 530-536, 2002.

[24] M. J. Van de Vijver, Y. D. He, L. J. Van 't Veer, et al., "A gene-expression signature as a predictor of survival in breast cancer," The New England Journal of Medicine, vol. 347, no. 25, pp. 1999-2009, 2002.

[25] P. J. M. Valk, R. G. W. Verhaak, M. A. Beijen, et al., "Prognostically useful gene-expression profiles in acute myeloid leukemia," The New England Journal of Medicine, vol. 350, no. 16, pp. 1617-1628, 2004.

[26] B. Lowenberg, H. R. Delwel, and P. J. M. Valk, "The diagnosis of acute myeloid leukaemia enhanced by using DNA microarrays," Nederlands Tijdschrift voor Geneeskunde, vol. 149, no. 12, pp. 623-625, 2005.

[27] P. Roepman, L. F. A. Wessels, N. Kettelarij, et al., "An expression profile for diagnosis of lymph node metastases from primary head and neck squamous cell carcinomas," Nature Genetics, vol. 37, no. 2, pp. 182-186, 2005. 
[28] M. J. Heller, A. H. Forster, and E. Tu, "Active microelectronic chip devices which utilize controlled electrophoretic fields for multiplex DNA hybridization and other genomic applications," Electrophoresis, vol. 21, no. 1, pp. 157-164, 2000.

[29] J.-M. Laval, P.-E. Mazeran, and D. Thomas, "Nanobiotechnology and its role in the development of new analytical devices," Analyst, vol. 125, no. 1, pp. 29-33, 2000.

[30] T. Vo-Dinh, B. M. Cullum, and D. L. Stokes, "Nanosensors and biochips: frontiers in biomolecular diagnostics," Sensors and Actuators B, vol. 74, no. 1-3, pp. 2-11, 2001.

[31] G. Guetens, K. Van Cauwenberghe, G. De Boeck, et al., "Nanotechnology in bio/clinical analysis," Journal of Chromatography B, vol. 739, no. 1, pp. 139-150, 2000.

[32] M. Han, X. Gao, J. Z. Su, and S. Nie, "Quantum-dot-tagged microbeads for multiplexed optical coding of biomolecules," Nature Biotechnology, vol. 19, no. 7, pp. 631-635, 2001.

[33] H. Xu, M. Y. Sha, E. Y. Wong, et al., "Multiplexed SNP genotyping using the Qbead system: a quantum dot-encoded microsphere-based assay," Nucleic Acids Research, vol. 31, no. 8, article e43, 2003.

[34] D. A. LaVan, D. M. Lynn, and R. Langer, "Moving smaller in drug discovery and delivery," Nature Reviews Drug Discovery, vol. 1, no. 1, pp. 77-84, 2002.

[35] S. Howorka, S. Cheley, and H. Bayley, "Sequence-specific detection of individual DNA strands using engineered nanopores," Nature Biotechnology, vol. 19, no. 7, pp. 636-639, 2001.

[36] G. Wu, R. H. Datar, K. M. Hansen, T. Thundat, R. J. Cote, and A. Majumdar, "Bioassay of prostate-specific antigen (PSA) using microcantilevers," Nature Biotechnology, vol. 19, no. 9, pp. 856-860, 2001.

[37] A. Majumdar, "Bioassays based on molecular nanomechanics," Disease Markers, vol. 18, no. 4, pp. 167-174, 2002.

[38] F. Patolsky, G. Zheng, O. Hayden, M. Lakadamyali, X. Zhuang, and C. M. Lieber, "Electrical detection of single viruses," Proceedings of the National Academy of Sciences of the United States of America, vol. 101, no. 39, pp. 14017-14022, 2004.

[39] M. Larkin, "Nanowires show potential as virus detectors," The Lancet Infectious Diseases, vol. 4, no. 11, p. 656, 2004.

[40] R. J. Chen, S. Bangsaruntip, K. A. Drouvalakis, et al., "Noncovalent functionalization of carbon nanotubes for highly specific electronic biosensors," Proceedings of the National Academy of Sciences of the United States of America, vol. 100, no. 9, pp. 4984-4989, 2003.

[41] A. K. Deisingh and M. Thompson, "Biosensors for the detection of bacteria," Canadian Journal of Microbiology, vol. 50, no. 2, pp. 69-77, 2004.

[42] J. G. E. Gardeniers and A. Van den Berg, "Lab-on-a-chip systems for biomedical and environmental monitoring," Analytical and Bioanalytical Chemistry, vol. 378, no. 7, pp. 1700-1703, 2004.

[43] E. X. Vrouwe, R. Luttge, and A. van den Berg, "Direct measurement of lithium in whole blood using microchip capillary electrophoresis with integrated conductivity detection," Electrophoresis, vol. 25, no. 10-11, pp. 1660-1667, 2004.

[44] S. M. Buck, Y.-E. L. Koo, E. Park, et al., "Optochemical nanosensor PEBBLEs: photonic explorers for bioanalysis with biologically localized embedding," Current Opinion in Chemical Biology, vol. 8, no. 5, pp. 540-546, 2004.

[45] J. P. Sumner, J. W. Aylott, E. Monson, and R. Kopelman, "A fluorescent PEBBLE nanosensor for intracellular free zinc," Analyst, vol. 127, no. 1, pp. 11-16, 2002.
[46] G. M. Lanza, R. Lamerichs, S. Caruthers, and S. A. Wickline, "Molecular imaging in MR with targeted paramagnetic nanoparticles," MedicaMundi, vol. 47, no. 1, pp. 34-39, 2003.

[47] K. C. P. Li, S. D. Pandit, S. Guccione, and M. D. Bednarski, "Molecular imaging applications in nanomedicine," Biomedical Microdevices, vol. 6, no. 2, pp. 113-116, 2004.

[48] S. K. Sahoo and V. Labhasetwar, "Nanotech approaches to drug delivery and imaging," Drug Discovery Today, vol. 8, no. 24, pp. 1112-1120, 2003.

[49] S. A. Wickline and G. M. Lanza, "Nanotechnology for molecular imaging and targeted therapy," Circulation, vol. 107, no. 8, pp. 1092-1095, 2003.

[50] P. A. Dayton and K. W. Ferrara, "Targeted imaging using ultrasound," Journal of Magnetic Resonance Imaging, vol. 16, no. 4, pp. 362-377, 2002.

[51] A. M. Morawski, P. M. Winter, K. C. Crowder, et al., "Targeted nanoparticles for quantitative imaging of sparse molecular epitopes with MRI," Magnetic Resonance in Medicine, vol. 51, no. 3, pp. 480-486, 2004.

[52] R. Weissleder, G. Elizondo, J. Wittenberg, C. A. Rabito, H. H. Bengele, and L. Josephson, "Ultrasmall superparamagnetic iron oxide: characterization of a new class of contrast agents for MR imaging," Radiology, vol. 175, no. 2, pp. 489-493, 1990.

[53] A. Jordan, "Nanotechnology and consequences for surgical oncology," Kongressband Deutsche Gesellschaft fur Chirurgie Kongress, vol. 119, pp. 821-828, 2002.

[54] M. Torabi, S. L. Aquino, and M. G. Harisinghani, "Current concepts in lymph node imaging," Journal of Nuclear Medicine, vol. 45, no. 9, pp. 1509-1518, 2004.

[55] J. W. M. Bulte, T. Douglas, B. Witwer, et al., "Magnetodendrimers allow endosomal magnetic labeling and in vivo tracking of stem cells," Nature Biotechnology, vol. 19, no. 12, pp. 1141-1147, 2001.

[56] S. Svenson and D. . Tomalia, "Dendrimers in biomedical applications-reflections on the field," Advanced Drug Delivery Reviews, vol. 57, no. 15, pp. 2106-2129, 2005.

[57] H. Kobayashi and M. W. Brechbiel, "Dendrimer-based nanosized MRI contrast agents," Current Pharmaceutical Biotechnology, vol. 5, no. 6, pp. 539-549, 2004.

[58] H. Kobayashi and M. W. Brechbiel, "Nano-sized MRI contrast agents with dendrimer cores," Advanced Drug Delivery Reviews, vol. 57, no. 15, pp. 2271-2286, 2005.

[59] M. Bruchez Jr., M. Moronne, P. Gin, S. Weiss, and A. P. Alivisatos, "Semiconductor nanocrystals as fluorescent biological labels," Science, vol. 281, no. 5385, pp. 2013-2016, 1998.

[60] W. J. Parak, T. Pellegrino, and C. Plank, "Labelling of cells with quantum dots," Nanotechnology, vol. 16, no. 2, pp. R9R25, 2005.

[61] T. M. Jovin, "Quantum dots finally come of age," Nature Biotechnology, vol. 21, no. 1, pp. 32-33, 2003.

[62] D. S. Lidke and D. J. Arndt-Jovin, "Imaging takes a quantum leap," Physiology, vol. 19, no. 6, pp. 322-325, 2004.

[63] X. Michalet, F. F. Pinaud, L. A. Bentolila, et al., "Quantum dots for live cells, in vivo imaging, and diagnostics," Science, vol. 307, no. 5709, pp. 538-544, 2005.

[64] X. Wu, H. Liu, J. Liu, et al., "Immunofluorescent labeling of cancer marker Her2 and other cellular targets with semiconductor quantum dots," Nature Biotechnology, vol. 21, no. 1, pp. 41-46, 2003. 
[65] B. Dubertret, P. Skourides, D. J. Norris, V. Noireaux, A. H. Brivanlou, and A. Libchaber, "In vivo imaging of quantum dots encapsulated in phospholipid micelles," Science, vol. 298, no. 5599, pp. 1759-1762, 2002.

[66] R. F. Uren, "Cancer surgery joins the dots," Nature Biotechnology, vol. 22, no. 1, pp. 38-39, 2004.

[67] S. Kim, Y. T. Lim, E. G. Soltesz, et al., "Near-infrared fluorescent type II quantum dots for sentinel lymph node mapping," Nature Biotechnology, vol. 22, no. 1, pp. 93-97, 2004.

[68] S. Shrivastava, "Nanomedicines: physiological principals of distribution," DJNB, vol. 3, no. 4, pp. 303-308, 2008.

[69] T. M. Allen and P. R. Cullis, "Drug delivery systems: entering the mainstream," Science, vol. 303, no. 5665, pp. 1818-1822, 2004.

[70] R. Langer, “Drug delivery and targeting," Nature, vol. 392, no. 6679, pp. 5-10, 1998.

[71] C.-K. Kim and S.-J. Lim, "Recent progress in drug delivery systems for anticancer agents," Archives of Pharmacal Research, vol. 25, no. 3, pp. 229-239, 2002.

[72] D. J. A. Crommelin, G. Storm, W. Jiskoot, R. Stenekes, E. Mastrobattista, and W. E. Hennink, "Nanotechnological approaches for the delivery of macromolecules," Journal of Controlled Release, vol. 87, no. 1-3, pp. 81-88, 2003.

[73] R. H. Müller and C. M. Keck, "Challenges and solutions for the delivery of biotech drugs-a review of drug nanocrystal technology and lipid nanoparticles," Journal of Biotechnology, vol. 113, no. 1-3, pp. 151-170, 2004.

[74] A. A. Gabizon, "Stealth liposomes and tumor targeting: one step further in the quest for the magic bullet," Clinical Cancer Research, vol. 7, no. 2, pp. 223-225, 2001.

[75] D. E. Owens III and N. A. Peppas, "Opsonization, biodistribution, and pharmacokinetics of polymeric nanoparticles," International Journal of Pharmaceutics, vol. 307, no. 1, pp. 93102, 2006.

[76] D. Akin, J. Sturgis, K. Ragheb, et al., "Bacteria-mediated delivery of nanoparticles and cargo into cells," Nature Nanotechnology, vol. 2, no. 7, pp. 441-449, 2007.

[77] Y. Matsumura and H. Maeda, "A new concept for macromolecular therapeutics in cancer chemotherapy: mechanism of tumoritropic accumulation of proteins and the antitumor agent smancs," Cancer Research, vol. 46, no. 12, pp. 63876392, 1986.

[78] S. M. Moghimi, A. C. Hunter, and J. C. Murray, "Longcirculating and target-specific nanoparticles: theory to practice," Pharmacological Reviews, vol. 53, no. 2, pp. 283-318, 2001.

[79] G. Xu, K.-T. Yong, I. Roy, et al., "Bioconjugated quantum rods as targeted probes for efficient transmigration across an in vitro blood-brain barrier," Bioconjugate Chemistry, vol. 19, no. 6, pp. 1179-1185, 2008.

[80] R. H. Müller and C. M. Keck, "Drug delivery to the brainrealization by novel drug carriers," Journal of Nanoscience and Nanotechnology, vol. 4, no. 5, pp. 471-483, 2004.

[81] K.-T. Yong, J. Qian, I. Roy, et al., "Quantum rod bioconjugates as targeted probes for confocal and two-photon fluorescence imaging of cancer cells," Nano Letters, vol. 7, no. 3, pp. 761-765, 2007.

[82] A. Quintana, E. Raczka, L. Piehler, et al., "Design and function of a dendrimer-based therapeutic nanodevice targeted to tumor cells through the folate receptor," Pharmaceutical Research, vol. 19, no. 9, pp. 1310-1316, 2002.
[83] M.-S. Hong, S.-J. Lim, Y.-K. Oh, and C.-K. Kim, "pHsensitive, serum-stable and long-circulating liposomes as a new drug delivery system," Journal of Pharmacy and Pharmacology, vol. 54, no. 1, pp. 51-58, 2002.

[84] A. S. Lubbe, C. Bergemann, H. Riess, et al., "Clinical experiences with magnetic drug targeting: a phase I study with $4^{\prime}$-epidoxorubicin in 14 patients with advanced solid tumors," Cancer Research, vol. 56, no. 20, pp. 4686-4693, 1996.

[85] C. Alexiou, R. Jurgons, R. J. Schmid, et al., "Magnetic drug targeting-biodistribution of the magnetic carrier and the chemotherapeutic agent mitoxantrone after locoregional cancer treatment," Journal of Drug Targeting, vol. 11, no. 3, pp. 139-149, 2003.

[86] Z. M. Saiyed, S. D. Telang, and C. N. Ramchand, "Application of magnetic techniques in the field of drug discovery and biomedicine," BioMagnetic Research and Technology, vol. 1, pp. 1-8, 2003.

[87] B. Radt, T. A. Smith, and F. Caruso, "Optically addressable nanostructured capsules," Advanced Materials, vol. 16, no. 23-24, pp. 2184-2189, 2004.

[88] J. L. Nelson, B. L. Roeder, J. C. Carmen, F. Roloff, and W. G. Pitt, "Ultrasonically activated chemotherapeutic drug delivery in a rat model," Cancer Research, vol. 62, no. 24, pp. 7280-7283, 2002.

[89] G. Kong, R. D. Braun, and M. W. Dewhirst, "Characterization of the effect of hyperthermia on nanoparticle extravasation from tumor vasculature," Cancer Research, vol. 61, no. 7, pp. 3027-3032, 2001.

[90] D. E. Meyer, B. C. Shin, G. A. Kong, M. W. Dewhirst, and A. Chilkoti, "Drug targeting using thermally responsive polymers and local hyperthermia," Journal of Controlled Release, vol. 74, no. 1-3, pp. 213-224, 2001.

[91] D. E. Meyer, G. A. Kong, M. W. Dewhirst, M. R. Zalutsky, and A. Chilkoti, "Targeting a genetically engineered elastin-like polypeptide to solid tumors by local hyperthermia," Cancer Research, vol. 61, no. 4, pp. 1548-1554, 2001.

[92] K. J. Widder, A. E. Senyei, and D. G. Scarpelli, "Magnetic microspheres: a model system for site specific drug delivery in vivo," Proceedings of the Society for Experimental Biology and Medicine, vol. 158, no. 2, pp. 141-146, 1978.

[93] K. J. Widder, A. E. Senyei, and D. F. Ranney, "Magnetically responsive microspheres and other carriers for the biophysical targeting of antitumor agents," Advances in Pharmacology and Chemotherapy, vol. 16, pp. 213-271, 1979.

[94] C. Alexiou, W. Arnold, R. J. Klein, et al., "Locoregional cancer treatment with magnetic drug targeting," Cancer Research, vol. 60, no. 23, pp. 6641-6648, 2000.

[95] A. S. Lubbe, C. Alexiou, and C. Bergemann, "Clinical applications of magnetic drug targeting," Journal of Surgical Research, vol. 95, no. 2, pp. 200-206, 2001.

[96] J. Koda, A. Venook, E. Walser, et al., "Phase I/II trial of hepatic intraarterial delivery of doxorubicin hydrochloride adsorbed to magnetic targeted carriers in patients with hepatocarcinoma," European Journal of Cancer, vol. 38, supplement 7, p. S18, 2002.

[97] M. W. Wilson, R. K. Kerlan Jr., N. A. Fidelman, et al., "Reginoal therapy with a magnetic targeted carrier bound to doxorubicin in a dual MR imaging/conventional angiography suite-initial experience with 4 patients," Radiology, vol. 230, no. 1, pp. 287-293, 2004.

[98] L. R. Hirsch, R. J. Stafford, J. A. Bankson, et al., "Nanoshellmediated nearinfrared thermal therapy of tumors under magnetic resonance guidance," Proceedings of the National 
Academy of Sciences of the United States of America, vol. 100, no. 23, pp. 13549-13554, 2003.

[99] D. P. O’Neal, L. R. Hirsch, N. J. Halas, J. D. Payne, and J. L. West, "Photo-thermal tumor ablation in mice using near infrared-absorbing nanoparticles," Cancer Letters, vol. 209, no. 2, pp. 171-176, 2004.

[100] M. Johannsen, B. Thiesen, A. Jordan, et al., "Magnetic fluid hyperthermia (MFH) reduces prostate cancer growth in the orthotopic Dunning R3327 rat model," Prostate, vol. 64, no. 3, pp. 283-292, 2005.

[101] A. Joshi, S. Punyani, S. S. Bale, H. Yang, T. Borca-Tasciuc, and R. S. Kane, "Nanotube-assisted protein deactivation," Nature Nanotechnology, vol. 3, no. 1, pp. 41-45, 2008.

[102] A. A. Bhirde, V. Patel, J. Gavard, et al., "Targeted killing of cancer cells in vivo and in vitro with EGF-directed carbon nanotube-based drug delivery," ACS Nano, vol. 3, no. 2, pp. 307-316, 2009.

[103] N. W. S. Kam, M. O’Connell, J. A. Wisdom, and H. Dai, “Carbon nanotubes as multifunctional biological transporters and near-infrared agents for selective cancer cell destruction," Proceedings of the National Academy of Sciences of the United States of America, vol. 102, no. 33, pp. 11600-11605, 2005.

[104] I. Hilger, R. Hergt, and W. A. Kaiser, "Use of magnetic nanoparticle heating in the treatment of breast cancer," IEE Proceedings Nanobiotechnology, vol. 152, no. 1, pp. 33-39, 2005.

[105] R. Hergt, S. Dutz, R. Müller, and M. Zeisberger, "Magnetic particle hyperthermia: nanoparticle magnetism and materials development for cancer therapy," Journal of Physics Condensed Matter, vol. 18, no. 38, pp. S2919-S2934, 2006.

[106] P. Moroz, S. K. Jones, and B. N. Gray, "Magnetically mediated hyperthermia: current status and future directions," International Journal of Hyperthermia, vol. 18, no. 4, pp. 267-284, 2002.

[107] R. W. Rand, H. D. Snow, D. G. Elliott, and G. M. Haskins, "Induction heating method for use in causing necrosis of neoplasm," US patent specification, 1985.

[108] S. Shrivastava, T. Bera, S. K. Singh, G. Singh, P. Ramachandrarao, and D. Dash, "Characterization of antiplatelet properties of silver nanoparticles," ACS Nano, vol. 3, no. 6, pp. 1357-1364, 2009.

[109] G. E. Park and T. J. Webster, "A review of nanotechnology for the development of better orthopedic implants," Journal of Biomedical Nanotechnology, vol. 1, no. 1, pp. 18-29, 2005.

[110] S. A. Catledge, M. D. Fries, Y. K. Vohra, et al., "Nanostructured ceramics for biomedical implants," Journal of Nanoscience and Nanotechnology, vol. 2, no. 3-4, pp. 293-312, 2002.

[111] T. J. Webster, R. W. Siegel, and R. Bizios, "Osteoblast adhesion on nanophase ceramics," Biomaterials, vol. 20, no. 13, pp. 1221-1227, 1999.

[112] T. J. Webster and J. U. Ejiofor, "Increased osteoblast adhesion on nanophase metals: Ti, Ti6Al4V, and CoCrMo," Biomaterials, vol. 25, no. 19, pp. 4731-4739, 2004.

[113] T. J. Webster, E. L. Hellenmeyer, and R. L. Price, "Increased osteoblast functions on theta+delta nanofiber alumina," Biomaterials, vol. 26, no. 9, pp. 953-960, 2005.

[114] K. M. Woo, V. J. Chen, and P. X. Ma, "Nano-fibrous scaffolding architecture selectively enhances protein adsorption contributing to cell attachment," Journal of Biomedical Materials Research Part A, vol. 67, no. 2, pp. 531-537, 2003.
[115] R. L. Price, K. M. Haberstroh, and T. J. Webster, "Enhanced functions of osteoblasts on nanostructed surfaces of carbon and alumina," Medical and Biological Engineering and Computing, vol. 41, no. 3, pp. 372-375, 2003.

[116] O. V. Salata, "Applications of nanoparticles in biology and medicine," Journal of Nanobiotechnology, vol. 2, no. 1, pp. 38, 2004.

[117] F. Heidenau, W. Mittelmeier, R. Detsch, et al., "A novel antibacterial titania coating: metal ion toxicity and in vitro surface colonization," Journal of Materials Science: Materials in Medicine, vol. 16, no. 10, pp. 883-888, 2005.

[118] R. L. Price, M. C. Waid, K. M. Haberstroh, and T. J. Webster, "Selective bone cell adhesion on formulations containing carbon nanofibers," Biomaterials, vol. 24, no. 11, pp. 1877$1887,2003$.

[119] S. Kay, A. Thapa, K. M. Haberstroh, and T. J. Webster, "Nanostructured polymer/nanophase ceramic composites enhance osteoblast and chondrocyte adhesion," Tissue Engineering, vol. 8, no. 5, pp. 753-761, 2002.

[120] B. Zhao, H. Hu, S. K. Mandal, and R. C. Haddon, "A bone mimic based on the self-assembly of hydroxyapatite on chemically functionalized single-walled carbon nanotubes," Chemistry of Materials, vol. 17, no. 12, pp. 3235-3241, 2005.

[121] R. Vasita and D. S. Katti, "Nanofibers and their applications in tissue engineering," International Journal of Nanomedicine, vol. 1, no. 1, pp. 15-30, 2006.

[122] R. G. Ellis-Behnke, Y.-X. Liang, S.-W. You, et al., "Nano neuro knitting: peptide nanofiber scaffold for brain repair and axon regeneration with functional return of vision," Proceedings of the National Academy of Sciences of the United States of America, vol. 103, no. 13, pp. 5054-5059, 2006.

[123] N. Huang, P. Yang, Y. X. Leng, et al., "Hemocompatibility of titanium oxide films," Biomaterials, vol. 24, no. 13, pp. 21772187,2003

[124] J. T. Santini Jr., M. J. Cima, and R. Langer, "A controlledrelease microchip," Nature, vol. 397, no. 6717, pp. 335-338, 1999.

[125] J. T. Santini Jr., A. C. Richards, R. A. Scheidt, M. J. Cima, and R. S. Langer, "Microchip technology in drug delivery," Annals of Medicine, vol. 32, no. 6, pp. 377-379, 2000.

[126] D. A. LaVan, T. McGuire, and R. Langer, "Small-scale systems for in vivo drug delivery," Nature Biotechnology, vol. 21, no. 10, pp. 1184-1191, 2003.

[127] E. Zrenner, "Will retinal implants restore vision?" Science, vol. 295, no. 5557, pp. 1022-1025, 2002.

[128] M. A. L. Nicolelis, "Actions from thoughts," Nature, vol. 409, no. 6818, pp. 403-407, 2001.

[129] M. A. L. Nicolelis, "Brain-machine interfaces to restore motor function and probe neural circuits," Nature Reviews Neuroscience, vol. 4, no. 5, pp. 417-422, 2003.

[130] M. A. L. Nicolelis and J. K. Chapin, "Controlling Roberts with the mind," Scientific American, vol. 287, no. 4, p. 46, 2002.

[131] M. D. Serruya, N. G. Hatsopoulos, L. Paninski, M. R. Fellows, and J. P. Donoghue, "Instant neural control of a movement signal," Nature, vol. 416, no. 6877, pp. 141-142, 2002.

[132] J. P. Donoghue, "Connecting cortex to machines: recent advances in brain interfaces," Nature Neuroscience, vol. 5, supplement, pp. 1085-1088, 2002.

[133] A. B. Schwartz, "Cortical neural prosthetics," Annual Review of Neuroscience, vol. 27, pp. 487-507, 2004.

[134] P. R. Kennedy, R. A. E. Bakay, M. M. Moore, K. Adams, and J. Goldwaithe, "Direct control of a computer from the human central nervous system," IEEE Transactions on Rehabilitation Engineering, vol. 8, no. 2, pp. 198-202, 2000. 
[135] Press report of Brown University, "Pilot study of mindto-movement device shows early promise," July 2008, http://www.news-medical.net/news/2004/10/10/5440.aspx.

[136] M. A. L. Nicolelis, "The amazing adventures of robotrat," Trends in Cognitive Sciences, vol. 6, no. 11, pp. 449-450, 2002.

[137] S. K. Talwar, S. Xu, E. S. Hawley, S. A. Weiss, K. A. Moxon, and J. K. Chapin, "Rat navigation guided by remote control," Nature, vol. 417, no. 6884, pp. 37-38, 2002.

[138] T. Stieglitz, "Considerations on surface and structural biocompatibility as prerequisite for long-term stability of neural prostheses," Journal of Nanoscience and Nanotechnology, vol. 4, no. 5, pp. 496-503, 2004.

[139] S. Raghava, G. Goel, and U. B. Kompella, "Ophthalmic applications of nanotechnology," in Ocular Transporters in Ophthalmic Diseases and Drug Delivery, J. T. Tink and C. J. Barnstable, Eds., vol. 7, pp. 415-435, Humana Press, Totowa, NJ, USA, 2008.

[140] K. A. Moxon, N. M. Kalkhoran, M. Markert, M. A. Sambito, J.L. McKenzie, and J. T. Webster, "Nanostructured surface modification of ceramic-based microelectrodes to enhance biocompatibility for a direct brain-machine interface," IEEE Transactions on Biomedical Engineering, vol. 51, no. 6, pp. 881-889, 2004.

[141] M. Arruebo, R. Fernandez-Pacheco, M. R. Ibarra, and J. Santamaria, "Magnetic nanoparticles for drug delivery," Nano Today, vol. 2, no. 3, pp. 22-32, 2007.

[142] M. Morrison, "Nanotechnology and its implications for the health of the EU citizen," Nanoforum,2003, http:// www.nanoforum.org/dateien/temp/Nanotechnology $\% 20$ and $\% 20$ its $\% 20$ Implication $\% 20$ for $\% 20$ the $\% 20$ Health \%20of\%20the\%20EU\%20Citizen\%20(18.12.03) .pdf?01072004120631.

[143] S. L. Tao and T. A. Desai, "Microfabricated drug delivery systems: from particles to pores," Advanced Drug Delivery Reviews, vol. 55, no. 3, pp. 315-328, 2003.

[144] B. Scrosati, "Nanomaterials: paper powers battery breakthrough," Nature Nanotechnology, vol. 2, no. 10, pp. 598-599, 2007.

[145] A. B. Lansdown, "Silver. I: its antibacterial properties and mechanism of action," Journal of Wound Care, vol. 11, no. 4, pp. 125-130, 2002.

[146] F. Furno, K. S. Morley, B. Wong, et al., "Silver nanoparticles and polymeric medical devices: a new approach to prevention of infection?" Journal of Antimicrobial Chemotherapy, vol. 54, no. 6, pp. 1019-1024, 2004.

[147] S. Shrivastava, "Nanofabrication for drug delivery and tissue engineering," Digest Journal of Nanomaterials and Biostructures, vol. 3, no. 4, pp. 257-263, 2008.

[148] U. Samuel and J. P. Guggenbichler, "Prevention of catheterrelated infections: the potential of a new nano-silver impregnated catheter," International Journal of Antimicrobial Agents, vol. 23, supplement 1, pp. S75-S78, 2004.

[149] V. Alt, T. Bechert, P. Steinrucke, et al., "Nanoparticulate silver. A new antimicrobial substance for bone cement," Orthopade, vol. 33, no. 8, pp. 885-892, 2004.

[150] V. Alt, T. Bechert, P. Steinrucke, et al., "An in vitro assessment of the antibacterial properties and cytotoxicity of nanoparticulate silver bone cement," Biomaterials, vol. 25, no. 18, pp. 4383-4391, 2004.

[151] A. B. Lansdown, "A guide to the properties and uses of silver dressings in wound care," Professional Nurse, vol. 20, no. 5, pp. 41-43, 2005.

[152] P.-C. Maness, S. Smolinski, D. M. Blake, Z. Huang, E. J. Wolfrum, and W. A. Jacoby, "Bactericidal activity of photocatalytic $\mathrm{TiO}_{2}$ reaction: toward an understanding of its killing mechanism," Applied and Environmental Microbiology, vol. 65, no. 9, pp. 4094-4098, 1999.

[153] Y. Kai, Y. Komazawa, A. Miyajima, N. Miyata, and Y. Yamakoshi, "[60]Fullerene as a novel photoinduced antibiotic," Fullerenes Nanotubes and Carbon Nanostructures, vol. 11, no. 1, pp. 79-87, 2003.

[154] R. Holladay, W. Moeller, D. Mehta, J. Brooks, R. Roy, and M. Mortenson, "Silver/water, silver gels and silver-based compositions, and methods for making and using the same," Application Number WO2005US47699 20051230 European Patent Office, 2006.

[155] "Radio-frequency identification: its potential in healthcare," Health Devices, vol. 34, no. 5, pp. 149-160, 2005.

[156] P. N. Valenstein and R. L. Sirota, "Identification errors in pathology and laboratory medicine," Clinics in Laboratory Medicine, vol. 24, no. 4, pp. 979-996, 2004.

[157] W. S. Sandberg, M. Hakkinen, M. Egan, et al., "Automatic detection and notification of "wrong patient-wrong location" errors in the operating room," Surgical Innovation, vol. 12, no. 3, pp. 253-260, 2005.

[158] N. Ahrens, A. Pruss, H. Kiesewetter, and A. Salama, "Failure of bedside ABO testing is still the most common cause of incorrect blood transfusion in the Barcode era," Transfusion and Apheresis Science, vol. 33, no. 1, pp. 25-29, 2005.

[159] H. J. Meyer, N. Chansue, and F. Monticelli, "Implantation of radio frequency identification device (RFID) microchip in disaster victim identification (DVI)," Forensic Science International, vol. 157, no. 2-3, pp. 168-171, 2006.

[160] S. Shrivastava and D. Dash, "Agrifood nanotechnology: a tiny revolution in food and agriculture," Journal of Nano Research. In press. 

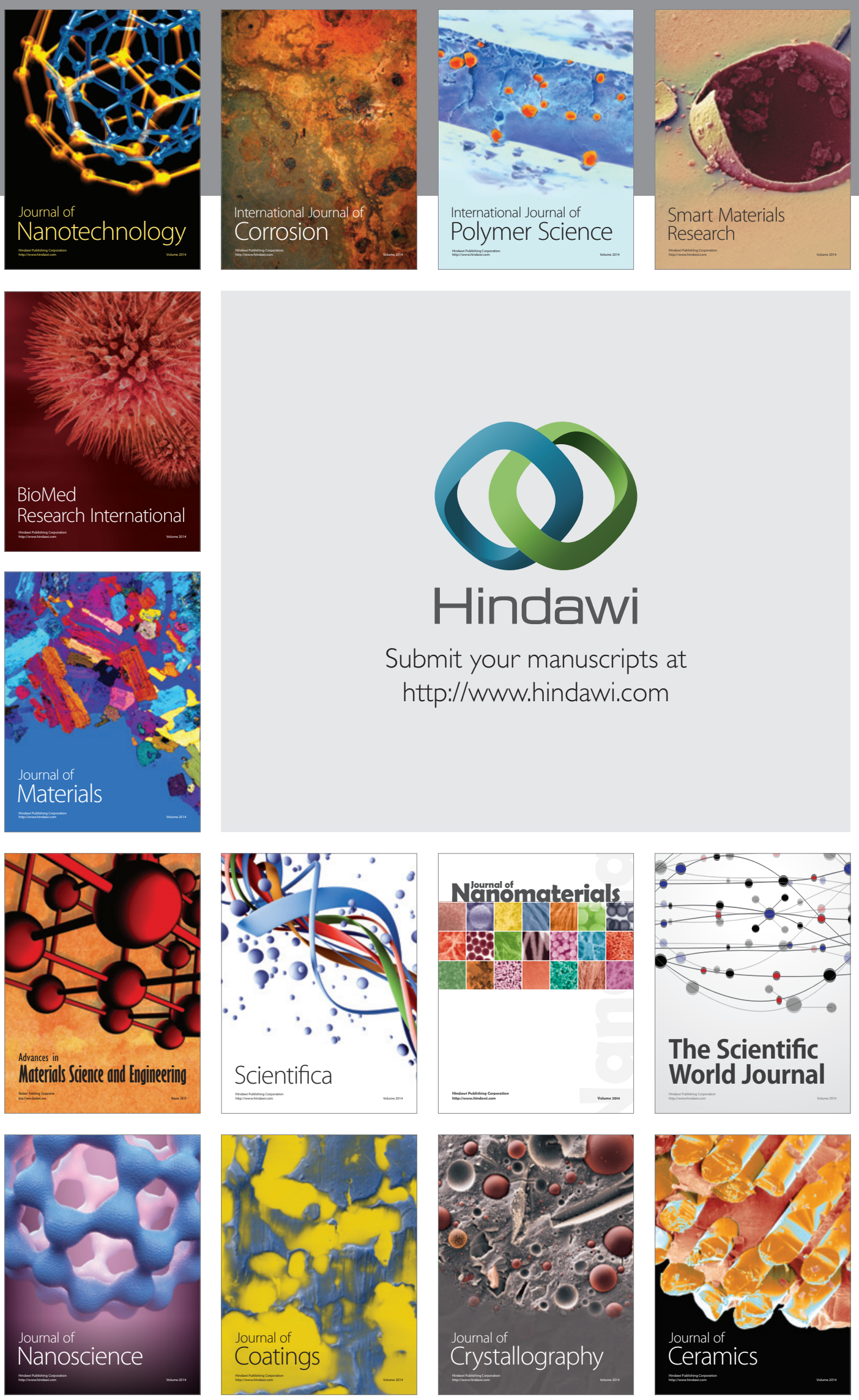

The Scientific World Journal

Submit your manuscripts at

http://www.hindawi.com

\section{World Journal}

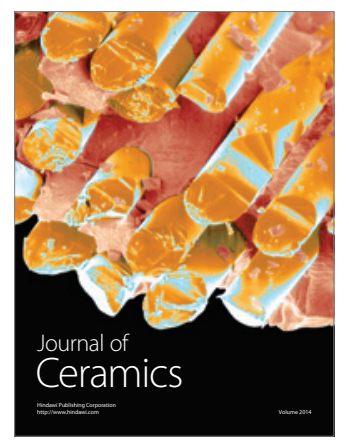

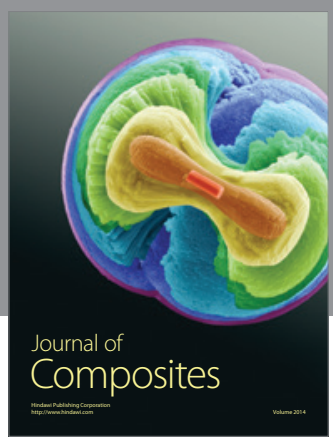
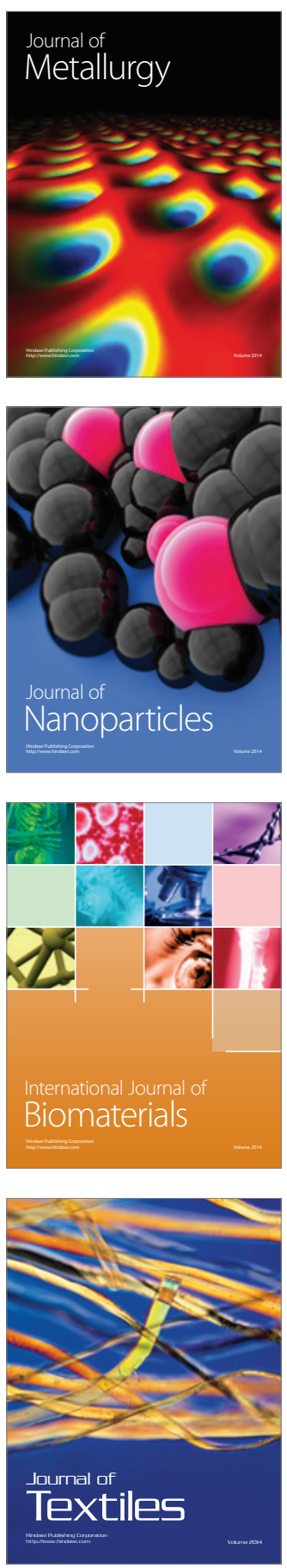